\title{
Artificial solid electrolyte interphase for suppressing surface reactions and cathode dissolution in aqueous zinc ion batteries
}

\author{
Jing Guo, ${ }^{1}$ Jun Ming, ${ }^{1}$ Yongjiu Lei, ${ }^{1}$ Wenli Zhang, ${ }^{1}$ Chuan Xia, ${ }^{1}$ Yi Cui,,${ }^{2,3^{*}}$ Husam N. Alshareef ${ }^{1 *}$ \\ ${ }^{1}$ Materials Science and Engineering, Physical Science and Engineering Division, King Abdullah \\ University of Science and Technology (KAUST), Thuwal 23955-6900, Saudi Arabia \\ ${ }^{2}$ Department of Materials Science and Engineering, Stanford University, Stanford, California 94305, \\ United States \\ ${ }^{3}$ Stanford Institute for Materials and Energy Sciences SLAC National Accelerator Laboratory, Menlo \\ Park, California 94025, United States
}

e-mail: yicui@stanford.edu; Husam.alshareef@kaust.edu.sa

\begin{abstract}
Vanadium-based compounds have been widely used as electrode materials in aqueous zinc ion batteries (ZIBs) due to the multiple oxidation states of vanadium and their open framework structure. However, the solubility of vanadium in aqueous electrolytes and the formation of byproducts during the charge/discharge process cause severe capacity fading and limit cycle life. Here, we report ultrathin $\mathrm{HfO}_{2}$ film as artificial solid electrolyte interphase (SEI) which is uniformly and conformally deposited by atomic layer deposition (ALD). The inactive Hafnium(IV) oxide $\left(\mathrm{HfO}_{2}\right)$ film not only decreases byproduct $\left(\mathrm{Zn}_{4} \mathrm{SO}_{4}(\mathrm{OH})_{6} \cdot \mathrm{xH}_{2} \mathrm{O}\right)$ formation on the surface of $\mathrm{Zn}_{3} \mathrm{~V}_{2} \mathrm{O}_{7}(\mathrm{OH})_{2} \cdot 2 \mathrm{H}_{2} \mathrm{O}(\mathrm{ZVO})$ but also suppresses the $\mathrm{ZVO}$ cathode dissolution in the electrolyte. As a result, the obtained $\mathrm{HfO}_{2}$-coated $\mathrm{ZVO}$ cathodes deliver higher capacity and better cycle life (227 mAh g $\mathrm{g}^{-1} @ 100 \mathrm{~mA} \mathrm{~g}{ }^{-1}$, 90\% retention over 100 cycles ) compared with pristine ZVO (170 mAh g $\mathrm{g}^{-1} @ 100 \mathrm{~mA} \mathrm{~g}^{-1}, 45 \%$ retention over 100 cycles ). A mechanistic investigation of the role of $\mathrm{HfO}_{2}$ is presented, along with data showing that our method constitutes a general strategy for other cathodes to enhance their performance in aqueous ZIBs.
\end{abstract}


Lithium-ion battery (LIB) is the most important energy storage technology, which has been widely employed in various applications. However, current commercial LIBs have some limitations such as flammable electrolyte, limited lithium supplies, and high cost.(1-4) These issues have motivated the search for alternative battery technologies such as rechargeable aqueous batteries. Compared with organic electrolytes, water-based electrolytes show high ionic conductivity $\left(\approx 1 \mathrm{~S} \mathrm{~cm}^{-1}\right)$, simple processing, and good safety.(5-9) Among the various aqueous batteries, rechargeable aqueous zinc ion batteries (RAZIBs) exhibit great promise due to Zinc having low redox potential $\left(-0.762 \mathrm{~V}\right.$ vs. SHE), high theoretical capacity $\left(819 \mathrm{mAh} \mathrm{g}^{-1}, 5851\right.$ $\left.\mathrm{mAh} \mathrm{mL}^{-1}\right)$, great earth abundance, and ease of material handling.(10-16)

To date, various materials have been reported as the cathode for RAZIBs (e.g. $\mathrm{MnO}_{2}$, Prussian blue analogues, polyanion compounds).(17-20) Among them, vanadium-based compounds with open framework structure possess higher energy density than other cathodes, which can be attributed to the multiple oxidation states of vanadium and their stable layered structure. $(21,22)$ Despite these advantages, vanadium-based compounds still suffer from fast capacity fading, but the reason remains unclear. The formation of inactive byproduct has been detected on the surface vanadium-based cathodes during the discharge process in previous works, an effect which was attributed to the reaction between $\mathrm{OH}^{-}$and $\mathrm{ZnSO}_{4}$ during the proton coinsertion process. $(23,24)$ Unfortunately, this insulating byproduct impedes the electrochemical reaction and causes increased resistance during repetitive cycling. The formation of $\mathrm{Zn}_{4} \mathrm{SO}_{4}(\mathrm{OH})_{6} \cdot \mathrm{xH}_{2} \mathrm{O}$ covers the cathode surface, leading to a decrease of electrochemically active surface area and hinder the movement of the electrons. In addition, vanadium-based cathodes are likely to dissolve in neutral/mildly acidic electrolytes as has been previously reported. $(25,26)$ The solubility of vanadium-based materials leads to direct capacity fading with cycling via loss of 
cathode active materials. Several approaches have been attempted to overcome these drawbacks. Chen et al. developed a mixed aqueous electrolyte consisting of both $\mathrm{Na}_{2} \mathrm{SO}_{4}$ and $\mathrm{ZnSO}_{4}$, which effectively inhibited the continuous dissolution of $\mathrm{NaV}_{3} \mathrm{O}_{8} \cdot 1.5 \mathrm{H}_{2} \mathrm{O}$.(24) $\mathrm{Na}_{2} \mathrm{SO}_{4}$ as an additive in the electrolyte not only changed the dissolution equilibrium between electrode and electrolyte but also suppressed Zn dendrite growth. Therefore, a good reversible capacity (380 mAh g-1@100 $\mathrm{mA} \mathrm{g}^{-1}$ ) and enhanced long-term cycling performance (82\% over 1000 cycles) were achieved for RAZIBs. Hu et al. deposited PEDOT with $5 \mathrm{~nm}$ thickness as a protective layer on the surface of $\mathrm{V}_{2} \mathrm{O}_{5}$ nanosheets, which improved zinc storage performance and promoted zinc ion and electron transport kinetics.(27) This hybrid PEDOT/ $\mathrm{V}_{2} \mathrm{O}_{5}$ electrode exhibited a specific capacity up to 232 $\mathrm{mAh} \mathrm{g}^{-1}$ at a large current density of $20 \mathrm{~A} \mathrm{~g}^{-1}$, and excellent cycle life (97\% retention after 600 cycles at $1 \mathrm{~A} \mathrm{~g}^{-1}$ and $89 \%$ after 1000 cycles).

Atomic layer deposition (ALD) is an effective method to coat uniform and conformal layers on complex and high-area surface structures via a sequential self-limiting gas/solid reaction.(28) The thickness of the ALD coating can be easily tailored at the atomic scale. ALD coating of $\mathrm{TiO}_{2}$,(29) $\mathrm{ZrO}_{2}$,(30) and $\mathrm{HfO}_{2}$,(31) have been proposed as surface passivation layers to improve the performance of LIB. The undesirable interfacial reactions between the electrodes and electrolytes could be effectively suppressed by using a passivating ALD layer. This passivation layer act as an artificial SEI in the rechargeable aqueous battery, which is important in determining the electrochemical performance of the electrode.(32) To the best of our knowledge, using the ALD surface engineering to improve zinc ion storage performance has not been reported.

Here, we demonstrate $\mathrm{HfO}_{2}$ coated $\mathrm{Zn}_{3} \mathrm{~V}_{2} \mathrm{O}_{7}(\mathrm{OH})_{2} \cdot 2 \mathrm{H}_{2} \mathrm{O}$ (denoted as $\mathrm{HfO}_{2}$-coated ZVO) effectively prevents cathode dissolution during cycling and largely decreases the formation of the insulating side products $\left(\mathrm{Zn}_{4} \mathrm{SO}_{4}(\mathrm{OH})_{6} \cdot \mathrm{xH}_{2} \mathrm{O}\right)$ at the electrode/electrolyte interface. As a result, 
functional RAZIB with $\mathrm{HfO}_{2}$-coated surface of $\mathrm{ZVO}$ cathode delivers higher specific capacity and better long-term cycling ability compared with the pristine ZVO.

The process of preparation for self-standing $\mathrm{HfO}_{2}$ coated $\mathrm{ZVO}$ electrode could be divided into two steps, as illustrated in Figure1. Firstly, ZVO nanobelts are prepared by the microwave synthesis and dispersed into deionized water with Super P, binder (carboxymethylcellulose (CMC) and styrene-butadiene rubber (SBR)) to form homogeneous dispersion (see details in Experimental section in the Supporting Information). The mixture is assembled by a facile vacuum filtration system, yielding film that could be easily peeled off from filter membranes to form a free-standing ZVO electrode. In the second step, the as-obtained electrodes are transferred into the ALD system for $\mathrm{HfO}_{2}$ surface deposition on $\mathrm{ZVO}$ at $180{ }^{\circ} \mathrm{C}$. To decrease the inner resistance, $\mathrm{HfO}_{2}$ is directly deposited on the assembled electrode instead of individual nanobelts followed by electrode making. Our way maintains direct interparticle electronic pathways without crossing the insulating $\mathrm{HfO}_{2}$ layer while $\mathrm{HfO}_{2}$ helps in "gluing" particles together. (33) The thickness of the $\mathrm{HfO}_{2}$ coating layer is simply controlled by the number of deposition cycles. After the ALD process, the morphology of the HfO-coated ZVO cathode is retained (Figure S1).

The crystal structure of pristine $\mathrm{ZVO}$ and $\mathrm{HfO}_{2}$-coated $\mathrm{ZVO}$ cathodes was studied by $\mathrm{X}$ ray diffraction (XRD). All the diffraction peaks obtained for both samples are indexed as $\mathrm{Zn}_{3} \mathrm{~V}_{2} \mathrm{O}_{7}(\mathrm{OH})_{2} \cdot 2 \mathrm{H}_{2} \mathrm{O}$ (JCPDS No. 50-0570) with no signs of impurity phases (Figure 2a). No different peaks corresponding to $\mathrm{HfO}_{2}$ could be observed in the XRD pattern, which is most likely due to its $5 \mathrm{~nm}$ thickness and amorphous state.(34) The chemical composition and bonding state of the $\mathrm{HfO}_{2}$-coated ZVO cathode were evaluated by X-ray photoelectron spectroscopy (XPS). The high resolution spectrum of V 2p is shown in Figure 2b. The peaks at 517.3 and $524.6 \mathrm{eV}$ can be ascribed to the $V 2 p_{3 / 2}$ and $V 2 p_{1 / 2}$ peaks of $V^{5+}$, which demonstrate that the chemical valence of 
vanadium has not been affected by the $\mathrm{HfO}_{2}$ coating.(35) The peaks around 17.0 and $18.7 \mathrm{eV}$ of the $\mathrm{Hf} 4 \mathrm{f}$ spectrum in Figure $2 \mathrm{c}$ are related to $4 \mathrm{f}_{5 / 2}$ and $4 \mathrm{f}_{7 / 2}$ respectively, which belong to the Hf$\mathrm{O}$ bonding in $\mathrm{HfO}_{2}$.(36) The XPS data on $\mathrm{Zn}$ and O (Figure S2a-b) exhibit signals that can be expected for the sample of $\mathrm{HfO}_{2}$ coated $\mathrm{ZVO}$, which matches well with the previous report for pure ZVO. Transmission electron microscopy (TEM), high angle annular dark-field scanning TEM (HAADF-STEM), and high-resolution TEM (HRTEM) were employed to provide structural information on the samples. As shown in Figure 2d, a clear interface between the core and shell is easily observed, which is related to the different atomic numbers of the atoms present in these two regions. In Figure 2e, a uniform $\mathrm{HfO}_{2}$ layer with thickness of $5 \mathrm{~nm}$ can be seen maintaining well-defined nanobelt morphology with a core-shell structure compared with pristine ZVO (Figure S3). The lattice spacing of $0.21 \mathrm{~nm}$ is observed in Figure 2f, which corresponds to the interplanar spacing of ZVO (022) planes. Elemental mapping was performed using energy dispersive X-ray spectroscopy (EDS), as shown in Figure $2 \mathrm{~g}-\mathrm{k}$. The $\mathrm{Zn}, \mathrm{V}, \mathrm{O}$, Hf elements are homogeneously distributed in the $\mathrm{HfO}_{2}$-coated $\mathrm{ZVO}$ nanobelts. These results demonstrate that the ultrathin $\mathrm{HfO}_{2}$ layer has been successfully deposited on the surface of ZVO free-standing electrode film.

The electrodes made by vacuum filtration were used as cathodes in aqueous ZIBs, where zinc foil and $1 \mathrm{M} \mathrm{ZnSO}_{4}$ were used as anode and electrolyte, respectively. Figure 3a shows the cyclic voltammetry (CV) plot obtained at a scan rate of $0.3 \mathrm{mV} \mathrm{s}^{-1}$ in the voltage window of $0.2-$ $1.8 \mathrm{~V}\left(\mathrm{vs} \mathrm{Zn} / \mathrm{Zn}^{2+}\right)$. The shape of the $\mathrm{CV}$ curves is similar for the two samples, indicating that the $\mathrm{HfO}_{2}$ layer does not significantly change the electrochemical reaction during $\mathrm{Zn}^{2+}$ de/intercalation. The RAZIBs with $\mathrm{HfO}_{2}$-coated $\mathrm{ZVO}$ cathode delivers a smaller polarization than pristine ZVO, which implies faster kinetics. To further understand the charge storage kinetics of these hosts, the diffusion-controlled and capacitive contributions were quantitatively determined from $\mathrm{CV}$ curves 
measured at different scan rates (Figure S4a,b), and the b values of six peaks were calculated (Figure $3 b$ ). The $\mathrm{b}$ values of $\mathrm{HfO}_{2}$-coated $\mathrm{ZVO}$ were $0.74,0.98,0.8,0.77,0.67$, and 0.84 , corresponding to peaks labeled as A1, A2, A3, C1, C2, C3 (Figure 3a), respectively. The b values for the $\mathrm{HfO}_{2}$-coated $\mathrm{ZVO}$ are higher than those of pristine $\mathrm{ZVO}$, suggesting enhanced reaction kinetics. $(37,38)$ The contribution ratio of capacitive-response to the whole capacity of $\mathrm{HfO}_{2}$-coated ZVO at the scan rate of $0.3 \mathrm{mV} \mathrm{s}^{-1}$ is $76.6 \%$, indicating pseudocapacitance-controlled electrochemical reactions (Figure S5). The rate performance is presented in Figure 3c, where the current density increases from $100 \mathrm{~mA} \mathrm{~g}^{-1}$ to $3000 \mathrm{~mA} \mathrm{~g}^{-1}$, then back to $500 \mathrm{~mA} \mathrm{~g}^{-1}$. The reversible discharge capacities of $\mathrm{HfO}_{2}$-coated ZVO cathode are 215, 190, 165, 120, 106 and $88 \mathrm{mAh} \mathrm{g}^{-1}$ at $100,300,500,800,1000$ and $3000 \mathrm{~mA} \mathrm{~g}^{-1}$, respectively. When the current density is reduced to $500 \mathrm{~mA} \mathrm{~g}^{-1}$, an average discharge capacity of $162 \mathrm{mAh} \mathrm{g}^{-1}$ can be recovered. At a low current density of $100 \mathrm{~mA} \mathrm{~g}^{-1}$ in Figure 3d, the $\mathrm{HfO}_{2}$-coated ZVO delivers $227 \mathrm{mAh} \mathrm{g}^{-1}$ and $90 \%$ capacity retention after 100 cycles. However, ZVO delivers a lower initial capacity and only $45 \%$ is retained after the same number of cycles, indicating rapid capacity degradation. To gain insight into the reason for the fast capacity fading in pristine ZVO, ICP-OES was conducted to determine the electrolyte composition during cycling (herein, a three-electrode electrolyzer was used to collect the electrolyte). As shown in Figure 3e, the electrode was immersed in the electrolyte for $2 \mathrm{~h}$ before testing. The vanadium detected in the electrolyte before electrochemical testing should be ascribed to the dissolved cathode material. The concentration of vanadium in the case of pristine ZVO increases with cycling, indicating that the vanadium corrosion becomes more serious due to the direct contact between the active material and the mild acidic electrolyte $(\mathrm{pH}=5.1)$. In comparison, the $\mathrm{HfO}_{2}$-coated $\mathrm{ZVO}$ cathode, much less vanadium dissolution, which is consistent with the better performance at low current density. As a general method, the artificial solid interphase can be 
applied for other materials (Figure S6). Even at a high rate of $10 \mathrm{~A} \mathrm{~g}^{-1}$ (Figure 3f), 84\% of the original capacity has been retained after 1000 cycles for $\mathrm{HfO}_{2}$-coated $\mathrm{ZVO}$ cathodes, which shows excellent long-term durability with negligible capacity decay compared to pristine ZVO electrode cathode (only $70 \%$ of the capacity is retained).

In order to get further information on the energy storage mechanism, ex-suit XRD and EIS experiments were carried out to analyze the pristine $\mathrm{ZVO}$ and $\mathrm{HfO}_{2}$-coated $\mathrm{ZVO}$ electrode during the charge/discharge process. As marked in Figure 4a, in the ex-situ XRD pattern of ZVO, upon deep charge to $0.2 \mathrm{~V}$ in the third cycle, the peak located at $24.7^{\circ}$ corresponding to (002) reflection shifts to lower angle, which is caused by the co-insertion of $\mathrm{H}_{2} \mathrm{O}$ and $\mathrm{Zn}^{2+}$. In the subsequent discharge process, the (002) reflection shifts back to its initial position due to the $\mathrm{Zn}^{2+}$ deintercalation, which indicates a reversible reaction related to $\mathrm{Zn}^{2+}$ uptake/removal from $\mathrm{ZVO}$ lattice. Most interestingly, apart from the peak shifting, a new group of peaks can be observed in the XRD pattern of ZVO. The peaks appear at $26^{\circ}, 27.6^{\circ}$ and $28.8^{\circ}$ are well assigned to $\mathrm{Zn}_{4} \mathrm{SO}_{4}(\mathrm{OH})_{6} \cdot \mathrm{xH}_{2} \mathrm{O}$, which is an insulating byproduct reported in previous literature.(39)The $\mathrm{Zn}_{4} \mathrm{SO}_{4}(\mathrm{OH})_{6} \cdot \mathrm{xH}_{2} \mathrm{O}$ has continuously formed with voltage decreasing and gradually diminished upon voltage reversal. The same phenomenon has also been found in previous work.(24)The reversible formation of $\mathrm{Zn}_{4} \mathrm{SO}_{4}(\mathrm{OH})_{6} \cdot \mathrm{xH}_{2} \mathrm{O}$ should be ascribed to the reaction between $\mathrm{ZVO}$ and electrolyte, which results in an insulating layer deposited on the cathode surface (Figure S7). It should be noted that this byproduct can significantly influence the electrochemical reaction during the discharge process, and this point also be proved by the ex-suit EIS measurement (Figure S8). The charge transfer resistance $\left(\mathrm{R}_{\mathrm{ct}}\right)$ of the two samples at different charge/discharge stages in the first cycle are shown in Figure $4 b-c$. Figure $4 b$ shows that $R_{c t}$ increases sharply during the discharge process (from 24.8 to $304.9 \Omega$ ) and reverts to near the original value (from 304.8 to 15.4 
$\Omega$ ) in the charging process. Dramatic changes take place in $\mathrm{R}_{\mathrm{ct}}$ during the whole process because the byproducts partly insulate the electrode surface, which leads to an increase in internal resistance and hinders elecctrons transportation. For the $\mathrm{HfO}_{2}$-coated $\mathrm{ZVO}$ electrode, the $\mathrm{R}_{\mathrm{ct}}$ changes more gradually compared to bare ZVO (Figure 4c). This result is can be attributed to the $\mathrm{HfO}_{2}$ layer, which acts as an artificial passive layer, effectively suppressing the $\mathrm{Zn}_{4} \mathrm{SO}_{4}(\mathrm{OH})_{6} \cdot \mathrm{xH}_{2} \mathrm{O}$ formation. It is worth mentioning that the $\mathrm{R}_{\mathrm{ct}}$ of $\mathrm{HfO}_{2}$-coated $\mathrm{ZVO}$ electrode is higher than pristine $\mathrm{ZVO}$ at the initial state which can be attributed to the low conductivity of $\mathrm{HfO}_{2}$. On the basis of these findings, we proposed the storage mechanism shown in Figure 4d-e. During the discharge process, $\mathrm{OH}^{-}$reacts with $\mathrm{ZnSO}_{4}$, resulting in a large amount of $\mathrm{Zn}_{4} \mathrm{SO}_{4}(\mathrm{OH})_{6} \cdot \mathrm{xH}_{2} \mathrm{O}$ formation on the $\mathrm{ZVO}$ surface (Figure $4 \mathrm{~d}$ ). $\mathrm{Zn}_{4} \mathrm{SO}_{4}(\mathrm{OH})_{6} \cdot \mathrm{xH}_{2} \mathrm{O}$ as an insulating byproduct, not only increases the internal resistance of the whole battery but also seriously impedes the reactions by decreasing the electrochemically active area during cyclings.(23) It will be detrimental to power capability and extended cycling. Ultrathin $\mathrm{HfO}_{2}$ layer deposited by the ALD approach can directly separate the electrode and electrolyte. On the one hand, the formation of the byproduct could be effectively suppressed due to the different properties of the interface, which leads to a higher capacity. On the other hand, the contact between cathode and electrolyte has been avoided by the $\mathrm{HfO}_{2}$ layer, alleviating the dissolution of active material. Meanwhile, the $\mathrm{Zn}^{2+}$ could transport through the interface quickly, indicating the $\mathrm{Zn}^{2+}$ diffusion kinetics do not affect by the passive layer because of the amorphous state of the $\mathrm{HfO}_{2}$ layer.

In conclusion, we have shown that the surface passivation of $\mathrm{ZVO}$ cathodes by $\mathrm{HfO}_{2}$ as an artificial SEI significantly enhances the performance of zinc ion batteries. When compared with pristine $\mathrm{ZVO}$, the $\mathrm{HfO}_{2}$-coated $\mathrm{ZVO}$ cathode exhibits largely enhanced capacity and cycling stability. The mechanism of capacity fading has been studied, which demonstrates that the artificial 
SEI $\mathrm{HfO}_{2}$ layer plays a bifunctional role during the cycling process. It works as a screen that isolates the electrode and electrolyte, reducing dissolution of active materials in the electrolyte and suppressing the formation of the insulating byproduct. This approach was demonstrated to work with other cathode materials, which shows the universality of our artificial SEI approach.

\section{Acknowledgments}

The research reported in this publication is supported by King Abdullah University of Science and Technology (KAUST).

\section{Reference}

1. Dunn, B., H. Kamath, and J.-M. Tarascon, Electrical energy storage for the grid: a battery of choices. Science 2011. 334(6058): p. 928-935.

2. J.-M. Tarascon and M. Armand, Issues and challenges facing. Nature 2001. 414(15): p. 359-367.

3. Armand, M. and J.-M. Tarascon, Building better batteries. Nature 2008. 451(7179): p. $652-657$.

4. Arico, A.S., Bruce, P., Scrosati, B., Tarascon, J.M. and Van Schalkwijk, Nanostructured materials for advanced energy conversion and storage devices. Nat.Mater. 2005. 4, p. 928935.

5. Pasta, M., C.D. Wessells, R.A. Huggins, and Y. Cui, A high-rate and long cycle life aqueous electrolyte battery for grid-scale energy storage. Nat.Commun. 2012. 3: p. 1149.

6. Wang, G., L. Fu, N. Zhao, L. Yang, Y. Wu, and H. Wu, An Aqueous Rechargeable Lithium Battery with Good Cycling Performance. Angew. Chem., 2007. 119(1-2): p. 299-301. 
7. Chen, L., Z. Guo, Y. Xia, and Y. Wang, High-voltage aqueous battery approaching $3 \mathrm{~V}$ using an acidic-alkaline double electrolyte. Chem. Commun. 2013. 49(22): p. 2204-2206.

8. Yan, J., J. Wang, H. Liu, Z. Bakenov, D. Gosselink, and P. Chen, Rechargeable hybrid aqueous batteries. J.Power Sources 2012. 216: p. 222-226.

9. Zuo, W., W. Zhu, D. Zhao, Y. Sun, Y. Li, J. Liu, and X.W. Lou, Bismuth oxide: a versatile high-capacity electrode material for rechargeable aqueous metal-ion batteries. Energy Environ. Sci. 2016. 9(9): p. 2881-2891.

10. Kundu, D., B.D. Adams, V. Duffort, S.H. Vajargah, and L.F. Nazar, A high-capacity and long-life aqueous rechargeable zinc battery using a metal oxide intercalation cathode. Nat. Energy 2016. 1(10),16119.

11. Zhang, L., L. Chen, X. Zhou, and Z. Liu, Towards High-Voltage Aqueous Metal-Ion Batteries Beyond 1.5 V: The Zinc/Zinc Hexacyanoferrate System. Adv. Energy Mater. 2015. 5(2),1400930.

12. He, P., M. Yan, G. Zhang, R. Sun, L. Chen, Q. An, and L. Mai, Layered VS 2 NanosheetBased Aqueous Zn Ion Battery Cathode. Adv. Energy Mater. 2017. 7(11), 1601920.

13. Lee, J., J.B. Ju, W.I. Cho, B.W. Cho, and S.H. Oh, Todorokite-type $\mathrm{MnO}_{2}$ as a zinc-ion intercalating material. Electrochim. Acta 2013. 112: p. 138-143.

14. Häupler, B., C. Rössel, A.M. Schwenke, J. Winsberg, D. Schmidt, A. Wild, and U.S. Schubert, Aqueous zinc-organic polymer battery with a high rate performance and long lifetime. NPG Asia Mater. 2016. 8(7): p. e283-e283.

15. Ming, F., H. Liang, Y. Lei, S. Kandambeth, M. Eddaoudi, and H.N. Alshareef, Layered $\mathrm{Mg}_{\mathrm{x}} \mathrm{V}_{2} \mathrm{O}_{5} \cdot \mathrm{nH}_{2} \mathrm{O}$ as Cathode Material for High-Performance Aqueous Zinc Ion Batteries. ACS Energy Lett. 2018. 3(10): p. 2602-2609. 
16. Alfaruqi, M.H., V. Mathew, J. Song, S. Kim, S. Islam, D.T. Pham, J. Jo, S. Kim, J.P. Baboo, Z. Xiu, K.-S. Lee, Y.-K. Sun, and J. Kim, Electrochemical Zinc Intercalation in Lithium Vanadium Oxide: A High-Capacity Zinc-Ion Battery Cathode. Chem. Mater. 2017. 29(4): p. $1684-1694$.

17. $\mathrm{Xu}, \mathrm{C} ., \mathrm{B} . \mathrm{Li}, \mathrm{H} . \mathrm{Du}$, and F. Kang, Energetic zinc ion chemistry: the rechargeable zinc ion battery. Angew. Chem., Int. Ed. 2012. 51(4): p. 933-935.

18. Trocoli, R. and F. La Mantia, An aqueous zinc-ion battery based on copper hexacyanoferrate. ChemSusChem 2015. 8(3): p. 481-485.

19. Li, G., Z. Yang, Y. Jiang, C. Jin, W. Huang, X. Ding, and Y. Huang, Towards polyvalent ion batteries: A zinc-ion battery based on NASICON structured $\mathrm{Na}_{3} \mathrm{~V}_{2}\left(\mathrm{PO}_{4}\right)_{3}$. Nano Energy 2016. 25: p. 211-217.

20. Li, W., K. Wang, S. Cheng, and K. Jiang, A long-life aqueous Zn-ion battery based on $\mathrm{Na}_{3} \mathrm{~V}_{2}\left(\mathrm{PO}_{4}\right)_{2} \mathrm{~F}_{3}$ cathode. Energy Storage Mater. 2018. 15: p. 14-21.

21. Xia, C., J. Guo, Y. Lei, H. Liang, C. Zhao, and H.N. Alshareef, Rechargeable Aqueous Zinc-Ion Battery Based on Porous Framework Zinc Pyrovanadate Intercalation Cathode. Adv. Mater. 2018. 30(5), 1705580.

22. Xia, C., J. Guo, P. Li, X. Zhang, and H.N. Alshareef, Highly Stable Aqueous Zinc-Ion Storage Using a Layered Calcium Vanadium Oxide Bronze Cathode. Angew. Chem., Int. Ed. 2018. 57(15): p. 3943-3948.

23. Jo, J.H., Y.-K. Sun, and S.-T. Myung, Hollandite-type Al-doped $\mathrm{VO}_{1.52}(\mathrm{OH})_{0.77}$ as a zinc ion insertion host material. J. Mater. Chem. A 2017. 5(18): p. 8367-8375. 
24. Wan, F., L. Zhang, X. Dai, X. Wang, Z. Niu, and J. Chen, Aqueous rechargeable zinc/sodium vanadate batteries with enhanced performance from simultaneous insertion of dual carriers. Nat. Commun. 2018. 9(1): p. 1656.

25. Qu, Q., Y. Zhu, X. Gao, and Y. Wu, Core-Shell Structure of Polypyrrole Grown on $\mathrm{V}_{2} \mathrm{O}_{5}$ Nanoribbon as High Performance Anode Material for Supercapacitors. Adv. Energy Mater. 2012. 2(8): p. 950-955.

26. Tang, W., X. Gao, Y. Zhu, Y. Yue, Y. Shi, Y. Wu, and K. Zhu, A hybrid of $\mathrm{V}_{2} \mathrm{O}_{5}$ nanowires and MWCNTs coated with polypyrrole as an anode material for aqueous rechargeable lithium batteries with excellent cycling performance. J. Mater. Chem. 2012. 22(38), pp.20143-20145.

27. Xu, D., H. Wang, F. Li, Z. Guan, R. Wang, B. He, Y. Gong, and X. Hu, Conformal Conducting Polymer Shells on $\mathrm{V}_{2} \mathrm{O}_{5}$ Nanosheet Arrays as a High-Rate and Stable Zinc-Ion Battery Cathode. Adv. Mater. Interfaces 2019. 6(2), 1801506.

28. Ahmed, B., C. Xia, and H.N. Alshareef, Electrode surface engineering by atomic layer deposition: A promising pathway toward better energy storage. Nano Today 2016. 11(2): p. 250-271.

29. Wang, H., G. Jia, Y. Guo, Y. Zhang, H. Geng, J. Xu, W. Mai, Q. Yan, and H.J. Fan, Atomic Layer Deposition of Amorphous $\mathrm{TiO}_{2}$ on Carbon Nanotube Networks and Their Superior Li and Na Ion Storage Properties. Adv. Mater. Interfaces 2016. 3(21), 1600375.

30. Liu, J., X. Li, M. Cai, R. Li, and X. Sun, Ultrathin atomic layer deposited $\mathrm{ZrO}_{2}$ coating to enhance the electrochemical performance of $\mathrm{Li}_{4} \mathrm{Ti}_{5} \mathrm{O}_{12}$ as an anode material. Electrochim. Acta 2013. 93: p. 195-201. 
31. Yesibolati, N., M. Shahid, W. Chen, M.N. Hedhili, M.C. Reuter, F.M. Ross, and H.N. Alshareef, $\mathrm{SnO}_{2}$ anode surface passivation by atomic layer deposited $\mathrm{HfO}_{2}$ improves Liion battery performance. Small 2014. 10(14): p. 2849-2858.

32. Zhi, J., A.Z. Yazdi, G. Valappil, J. Haime, and P. Chen, Artificial solid electrolyte interphase for aqueous lithium energy storage systems. Sci. Adv. 2017. 3(9): p. e1701010.

33. Jung, Y.S., A.S. Cavanagh, L.A. Riley, S.H. Kang, A.C. Dillon, M.D. Groner, S.M. George, and S.H. Lee, Ultrathin direct atomic layer deposition on composite electrodes for highly durable and safe Li-ion batteries. Adv. Mater. 2010. 22(19): p. 2172-2176.

34. Ahmed, B., D.H. Anjum, M.N. Hedhili, and H.N. Alshareef, Mechanistic Insight into the Stability of $\mathrm{HfO}_{2}$-Coated $\mathrm{MoS}_{2}$ Nanosheet Anodes for Sodium Ion Batteries. Small 2015. 11(34): p. 4341-4350.

35. Jiang, H.-q., H. Endo, H. Natori, M. Nagai, and K. Kobayashi, Fabrication and efficient photocatalytic degradation of methylene blue over $\mathrm{CuO} / \mathrm{BiVO}_{4}$ composite under visiblelight irradiation. Mater. Res. Bull. 2009. 44(3): p. 700-706.

36. Zhang, L., M. Liu, W. Ren, Z. Zhou, G. Dong, Y. Zhang, B. Peng, X. Hao, C. Wang, Z.D. Jiang, W. Jing, and Z.-G. Ye, ALD preparation of high-k $\mathrm{HfO}_{2}$ thin films with enhanced energy density and efficient electrostatic energy storage. RSC Adv. 2017. 7(14): p. 83888393.

37. Kim, H.S., J.B. Cook, H. Lin, J.S. Ko, S.H. Tolbert, V. Ozolins, and B. Dunn, Oxygen vacancies enhance pseudocapacitive charge storage properties of $\mathrm{MoO}_{3-\mathrm{x} .}$ Nat. Mater. 2017. 16(4): p. 454-460. 
38. Augustyn, V., J. Come, M.A. Lowe, J.W. Kim, P.L. Taberna, S.H. Tolbert, H.D. Abruna, P. Simon, and B. Dunn, High-rate electrochemical energy storage through $\mathrm{Li}^{+}$intercalation pseudocapacitance. Nat. Mater. 2013. 12(6): p. 518-522.

39. Chamoun, M., W.R. Brant, C.-W. Tai, G. Karlsson, and D. Noréus, Rechargeability of aqueous sulfate $\mathrm{Zn} / \mathrm{MnO}_{2}$ batteries enhanced by accessible $\mathrm{Mn}^{2+}$ ions. Energy Storage Mater. 2018. 15: p. 351-360. 


\section{Figures}

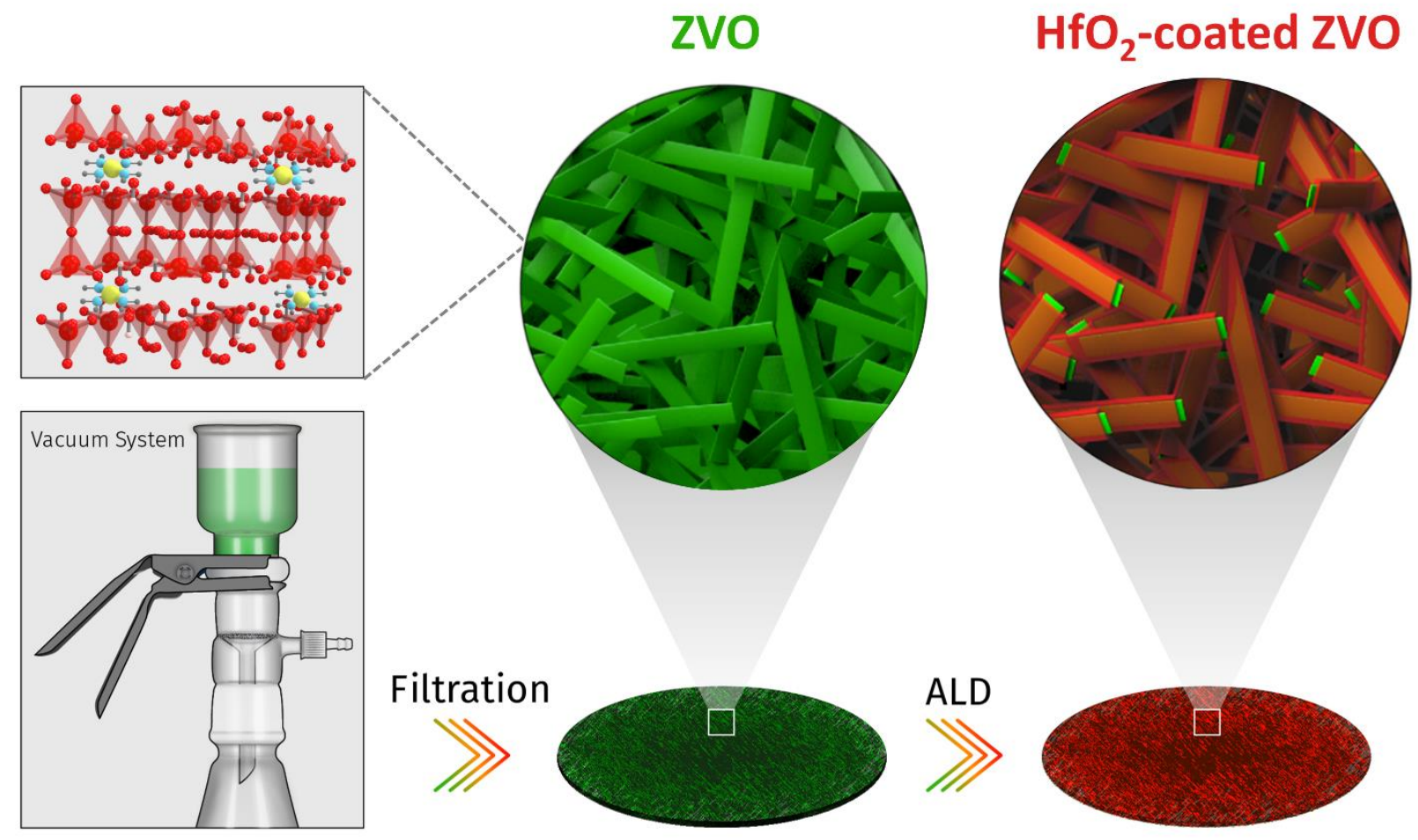

Figure 1. Schematic illustration of the fabrication process of pristine $\mathrm{ZVO}$ cathode and the $\mathrm{HfO}_{2}$ coated ZVO by atomic layer deposition (ALD). The ALD coating acts as an artificial solid interphase layer, which significantly improves the performance and stability of the ZIB cathodes. 

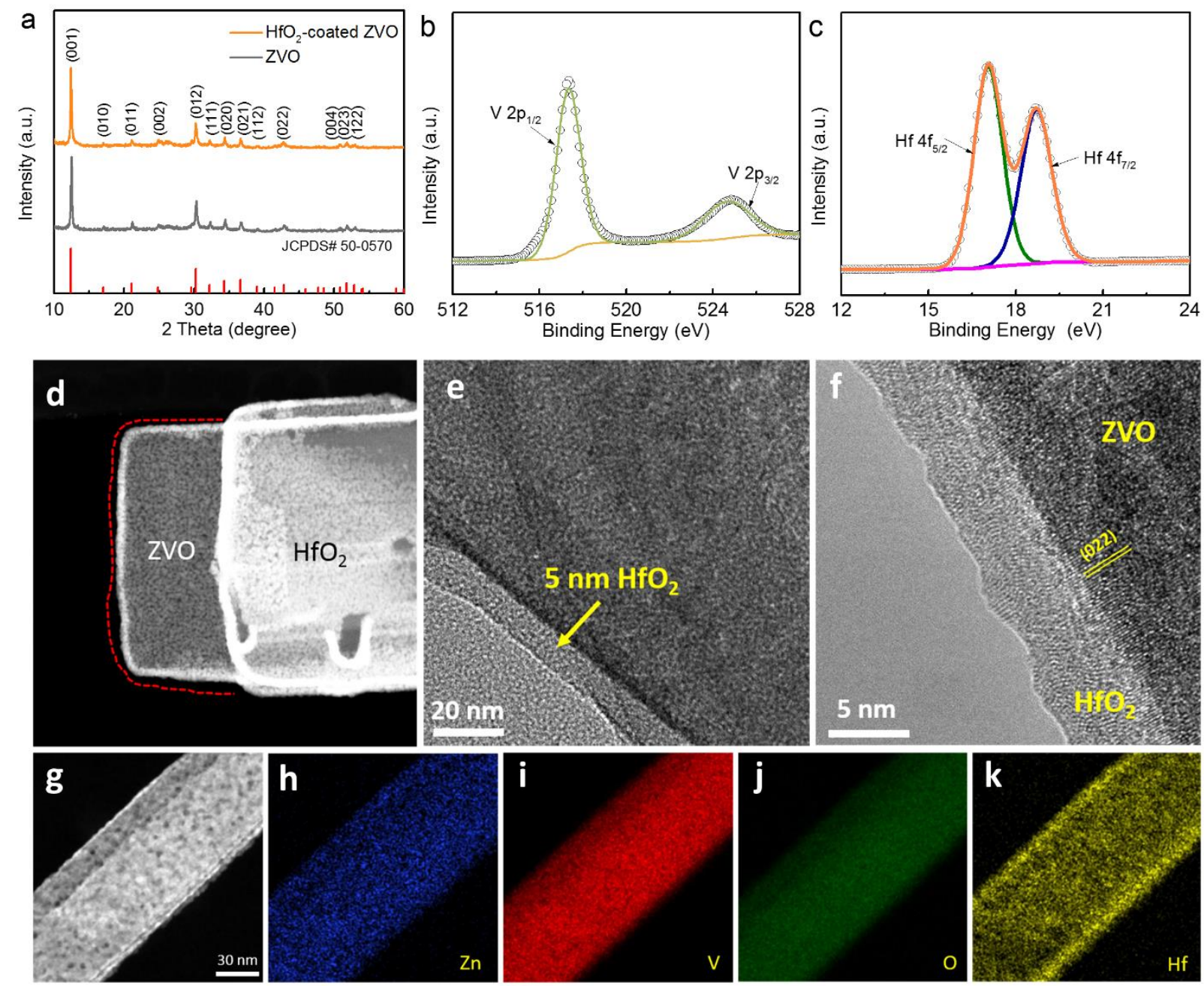

Figure 2. Morphology and structure of as-prepared $\mathrm{HfO}_{2}$-coated $\mathrm{ZVO}$ and pristine $\mathrm{ZVO}$ cathodes. a) XRD pattern showing the $\mathrm{HfO}_{2}$ coating does not change the $\mathrm{ZVO}$ cathode structure. b-c) XPS high-resolution spectra of (b) $\mathrm{V} 2 \mathrm{p}$ and (c) $\mathrm{Hf} 4 \mathrm{f}$ obtained from $\mathrm{HfO}_{2}$-coated ZVO. d) HAADFSTEM image e) TEM image f) HRTEM image of $\mathrm{HfO}_{2}$-coated ZVO. g-k) TEM-EDS elemental maps of $\mathrm{HfO}_{2}$-coated $\mathrm{ZVO}$ individual nanobelt. 

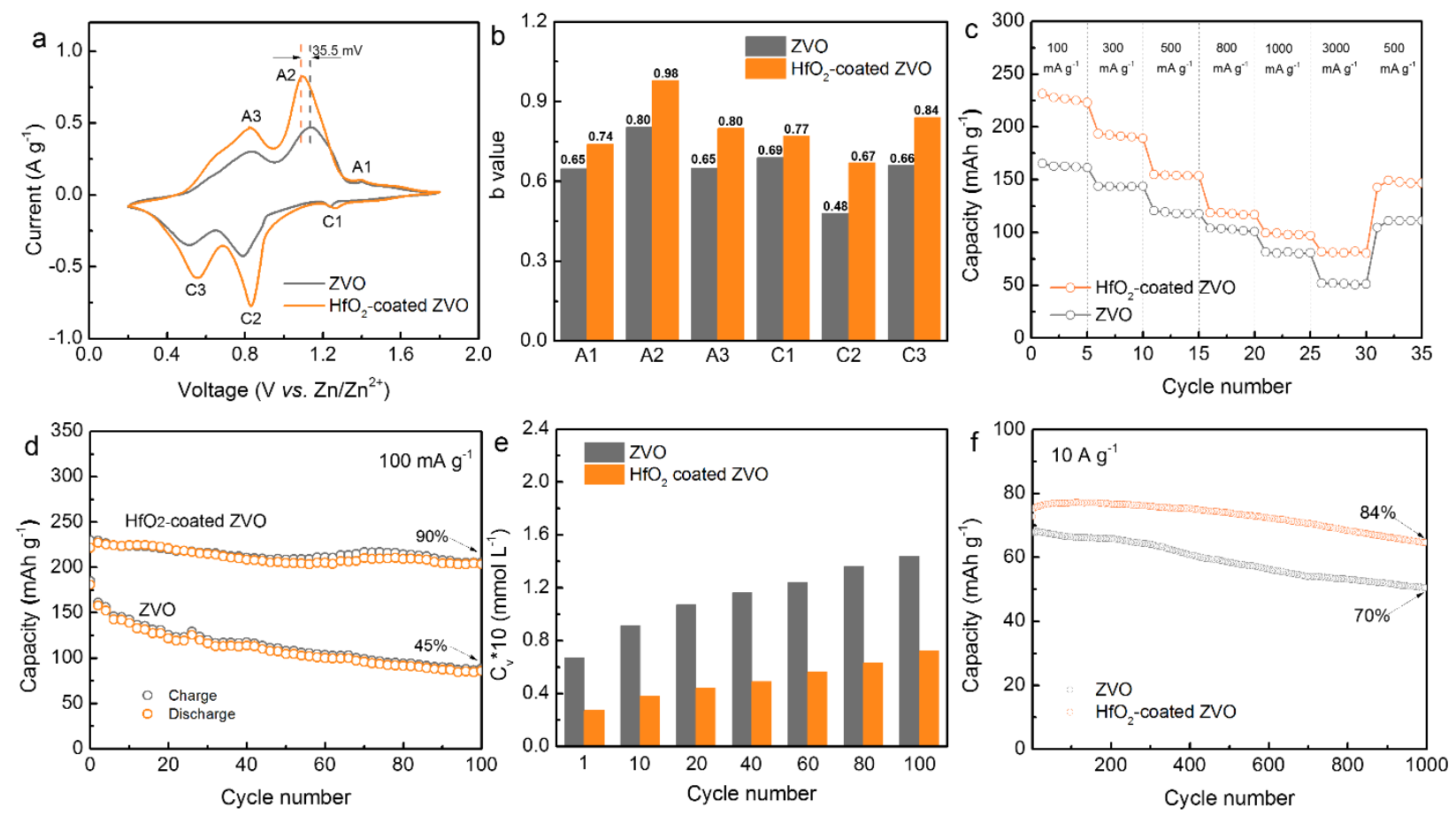

Figure 3. Electrochemical performance of the $\mathrm{HfO}_{2}$-coated $\mathrm{ZVO}$ and pristine $\mathrm{ZVO}$ cathodes: a) $\mathrm{CV}$ curves measured at a scan rate of $0.3 \mathrm{mV} \mathrm{s}^{-1} ; \mathrm{b}$ ) The $\mathrm{b}$ value for different redox peaks determined from the $\log (\mathrm{i})$ versus $\log (\mathrm{v})$ plots; c) Rate performance; d) Cycling performance at current density of $100 \mathrm{~mA} \mathrm{~g}^{-1}$; e) ICP-OES results after different number of cycles; f) Cycling performance at current density of $10 \mathrm{~A} \mathrm{~g}^{-1}$. 

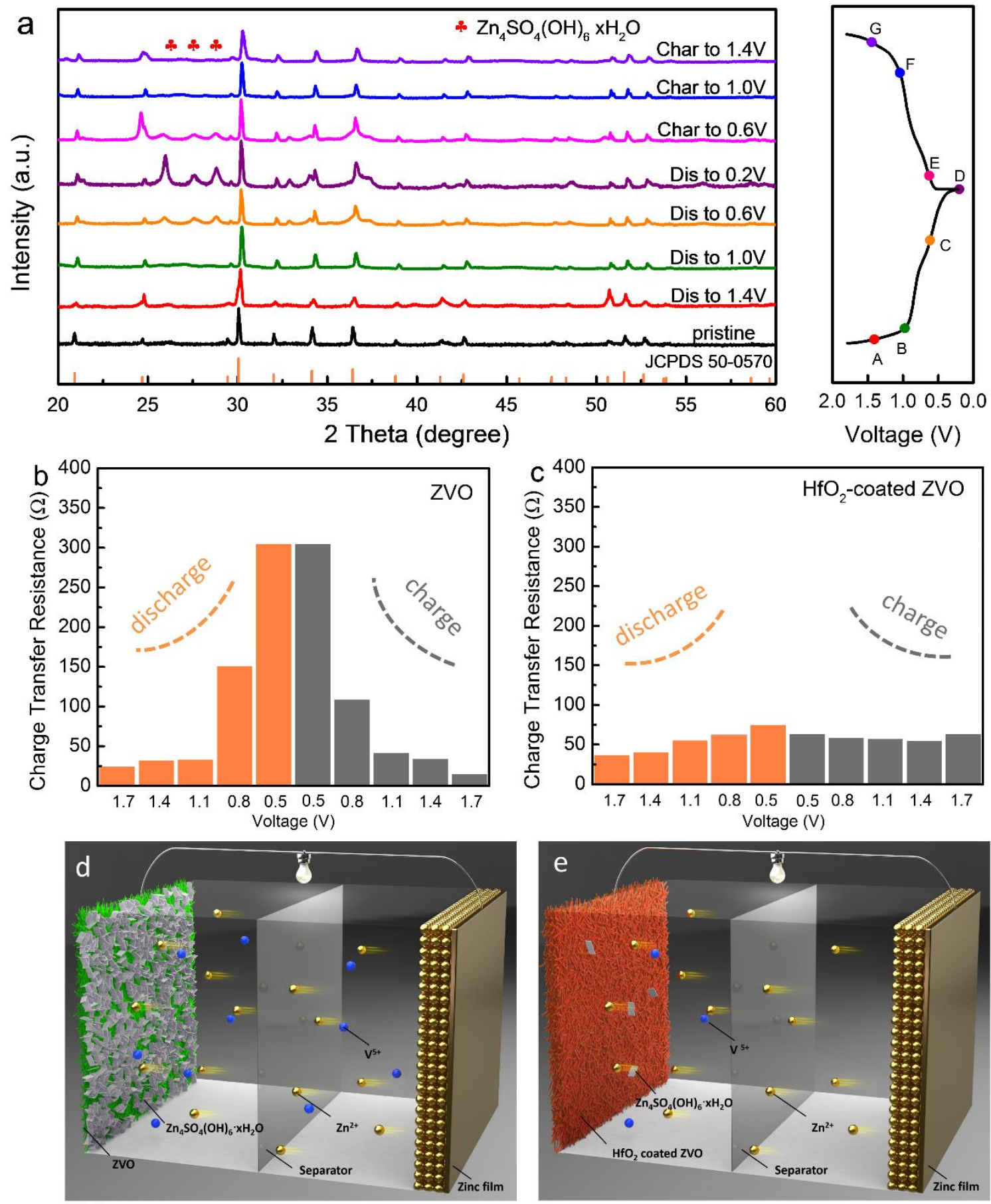

Figure 4. a) XRD characterization of the ZVO cathode during the charging and discharging process. The charge transfer resistance of b) uncoated $\mathrm{ZVO}$ and c) $\mathrm{HfO}_{2}$-coated $\mathrm{ZVO}$ during the charge and discharge process. A more gradual change in the charge transfer resistance is seen in the case of $\mathrm{HfO}_{2}$-coated ZVO. Schematic illustration of the RAZIB storage mechanism with d) ZVO and e) the $\mathrm{HfO}_{2}$-coated ZVO cathode. Color: (blue, dissolved V ions), (gold, $\mathrm{Zn}$ ). 
TOC

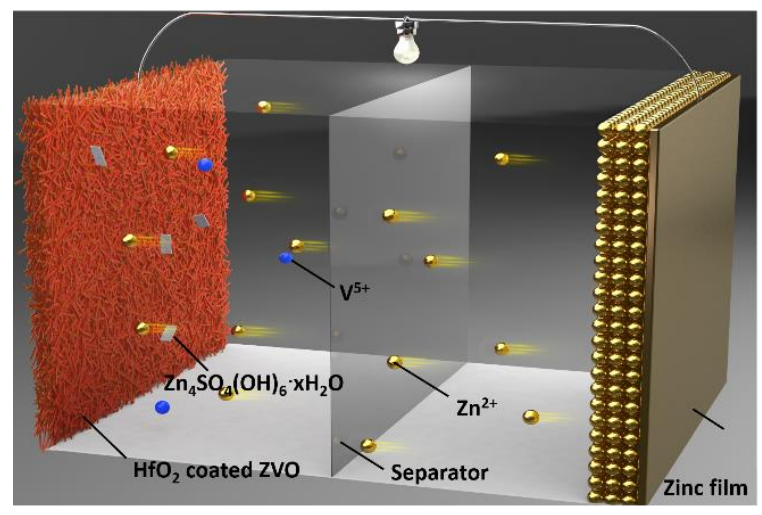

Compared with the pristine $\mathrm{ZVO}$ electrode, the $\mathrm{HfO}_{2}$ layer act as an artificial solid electrolyte interphase that suppresses the formation of byproduct at the interface between electrode and electrolyte. On the other hand, it also reduces cathode dissolution in the electrolyte. 